\title{
Clozapine as an Effective Antipsychotic in Treatment Resistant Mania: Two Case Reports
}

\author{
Mohamed Habib Aoun ${ }^{1,2}$, Rabaa Jomli ${ }^{3,4,}$, Hend Jemli ${ }^{4}$, Dorsaf Habbachi ${ }^{4}$, Yosra Zgueb ${ }^{3,4}$, \\ Uta Ouali ${ }^{3,4}$ \\ ${ }^{1}$ Psychiatry Department, Mahdia Hospital, Mahdia, Tunisia \\ ${ }^{2}$ Faculty of Medicine of Monastir, University Monastir, Monastir, Tunisia \\ ${ }^{3}$ Psychiatry Department (A), Razi Hospital, La Manouba, Tunisia \\ ${ }^{4}$ Faculty of Medicine of Tunis, University Tunis El Manar, Tunis, Tunisia
}

Email address:

rabaa.jomli@fmt.utm.tn (R. Jomli)

${ }^{*}$ Corresponding author

\section{To cite this article:}

Mohamed Habib Aoun, Rabaa Jomli, Hend Jemli, Dorsaf Habbachi, Yosra Zgueb, Uta Ouali. Clozapine as an Effective Antipsychotic in Treatment Resistant Mania: Two Case Reports. American Journal of Psychiatry and Neuroscience. Vol. 9, No. 3, 2021 , pp. $107-109$. doi: 10.11648/j.ajpn.20210903.15

Received: July 13, 2021; Accepted: July 24, 2021; Published: August 7, 2021

\begin{abstract}
Bipolar mood disorder (BD) is a severe debilitating mental disorder, and a number of patients are resistant to standard treatment. We report two clinical cases of treatment resistant mania (TRM) responsive to clozapine. Mrs. A and Mrs. $\mathrm{B}$ are two BD patients aged 30-year-old and 34-year-old respectively. They had a similar age of BD onset at 16 years old. They both had five manic episodes at least before they had the TRM. Mrs. A had a history of allergy to haloperidol. She presented a manic episode that was unresponsive to olanzapine $20 \mathrm{mg}$ daily, risperidone $4 \mathrm{mg}$ daily and lithium 1,250 mg daily. Mrs. B had a history of a mania non-responsive to the association of lithium and olanzapine $20 \mathrm{mg}$ daily and a history of severe depression under lithium and haloperidol $30 \mathrm{mg}$ daily. She presented a manic episode resisting the association of lithium $1000 \mathrm{mg}$ daily, carbamazepine $600 \mathrm{mg}$ daily, quetiapine $100 \mathrm{mg}$ daily and chlorpromazine $150 \mathrm{mg}$ daily. They both eventually received clozapine uptitrated gradually to $300 \mathrm{mg}$ daily with lithium (1,000-1,250 mg daily) with satisfactory clinical response within three weeks of starting clozapine. Clozapine seems to be efficacious in TRM. Further randomized clinical trials are needed to strengthen its evidence based indication in TRM.
\end{abstract}

Keywords: Bipolar Disorder, Antipsychotic, Treatment, Effectiveness

\section{Introduction} $[1]$.

Bipolar Disorder (BD) is a chronic, severe mental disorder

Aggregate estimates of the prevalence of BD indicate that approximately $1.0 \%$ of the general population meet lifetime criteria for BD type I (BD-I) [2].

$\mathrm{BD}$ is often associated with high levels of unfavorable outcomes or treatment resistance [3].

A working definition of Treatment Resistant Mania (TRM) is a manic $\mathrm{BD}$ phase non-responsive to at least two trials of dissimilar treatments of adequate dose and duration [4].

Very few treatment guidelines for this complex and severe illness were published $[5,6]$.
Clozapine, an atypical antipsychotic (AA), remains underused in TRM of resistant mania, despite increasing case reports, retrospective studies and randomised controlled trials suggesting that it may be particularly effective in TRM $[3,4$, 6-10].

\section{Methodology}

The case reports of the patients were retrieved and reviewed together with relevant literatures. 


\section{Case Reports}

\subsection{Case Report 1}

Mrs. A is a 34-year-old single woman with an 18-year history of BD I.

Her family history revealed chronic psychosis among her maternal uncle and BD I among her two maternal aunts.

She had a history of two manic episodes with psychotic features.

She had an allergy to the following psychotropic drugs: haloperidol, chlorpromazine, prazepam, biperiden.

She had four manic episodes with mixed features, with a history of non-compliance to therapy.

The last manic episode responded to a combination of lithium $1250 \mathrm{mg} /$ day, olanzapine $20 \mathrm{mg} /$ day, risperidone 4 $\mathrm{mg}$ /day and clonazepam $10 \mathrm{mg} /$ day.

She was eventually admitted into our department for a manic episode with mixed features that lasted for two months despite good therapeutic adherence.

Her complete blood count, electrocardiogram and electroencephalogram did not reveal any abnormality.

She was prescribed a combination of lithium $1250 \mathrm{mg} /$ day and clozapine.

Clozapine was gradually uptitrated to $300 \mathrm{mg} /$ day (at night), with close monitoring of white blood cell count and absolute neutrophil count.

She was able to be discharged from our department after 23 days.

She had her check-ups regularly after her discharge.

\subsection{Case Report 2}

Mrs. B is a 30-year-old married woman with a 14-year history of BD I.

Her family history revealed BD I in her maternal uncle and her maternal aunt.

She has a history of eight depressive episodes alternating with hypomanic episodes, with seasonal features, followed by five severe manic episodes with psychotic features.

The last manic episode occurred despite good therapeutic compliance to lithium $1,000 \mathrm{mg}$ daily and olanzapine $20 \mathrm{mg}$ daily. She was then prescribed lithium 1,000 $\mathrm{mg}$ and haloperidol $30 \mathrm{mg}$ daily.

With this combination, the patient developed a severe depressive episode, which was handled by lithium and quetiapine.

She later presented a manic episode with psychotic features that lasted for two months and was unresponsive to lithium 1,000 mg/day, quetiapine $100 \mathrm{mg} /$ day, carbamazepine $600 \mathrm{mg}$ daily and chlorpromazine $150 \mathrm{mg}$ daily.

She was eventually hospitalized in our department. After routine tests and an unremarkable electroencephalogram, clozapine was uptitrated to $300 \mathrm{mg}$ daily with lithium 1,000 $\mathrm{mg}$ daily. We got a favorable response after 28 days.

\section{Discussion}

Multiple studies have established that clozapine may be efficacious and relatively safe in TRM [3, 6-10]. In China, for instance, clozapine is a treatment of choice for TRM [3, 11]; while it remains uncommon in Western nations psychiatric practices [3].

We reported two clinical cases of TRM responsive to clozapine. Both patients had family history of BD and they both had a similar illness onset age of 16 years old. They had a history of at least five manic episodes before the TRM.

In the first case report, Mrs. A presented a manic episode that was resistant to two AA (olanzapine $20 \mathrm{mg}$ daily and risperidone $4 \mathrm{mg}$ daily) associated with lithium 1,250 mg daily. She had otherwise a history of allergy to haloperidol.

Regarding the second case, Mrs. B had a history of mania unresponsive to the association of lithium and olanzapine 20 $\mathrm{mg}$ /day and a history of severe depression under lithium and haloperidol $30 \mathrm{mg} /$ day. Her current manic episode was unresponsive to the association of lithium $1000 \mathrm{mg} /$ day, carbamazepine $600 \mathrm{mg} /$ day, quetiapine $100 \mathrm{mg}$ /day and chlorpromazine $150 \mathrm{mg} /$ day.

Both patients received clozapine uptitrated to $300 \mathrm{mg} /$ day prescribed at night and lithium (1,000-1,250 mg daily). Remission was obtained after 3 weeks in both cases. Clozapine monitoring guidelines were applied and no reported side effects warranted its discontinuation.

A similar case of TRM responsive to clozapine was published in 2016 [13]. A 17-year-old male patient with a 2year diagnosis of BP I presented a fourth manic episode that was unresponsive to risperidone $12 \mathrm{mg}$ daily for 4 weeks, olanzapine $30 \mathrm{mg}$ daily for 3 weeks, and haloperidol $30 \mathrm{mg}$ daily for 3 weeks, along with valproate preparation $1500 \mathrm{mg}$ daily. [13]. Remission was obtained with valproate 1,500 $\mathrm{mg}$ /day and clozapine $100 \mathrm{mg}$ /day in divided doses [13].

Another case report of TRM responsive to clozapine was published in 2020 [14]. A 22 year-old woman, with a 3-year history of BD I, presented eight days post-partum an unresponsive mania to olanzapine $20 \mathrm{mg}$ /day and to haloperidol $30 \mathrm{mg} /$ day both prescribed during three weeks each along with valproate preparation $1500 \mathrm{mg}$ daily. Clozapine was then introduced and uptitrated gradually to $150 \mathrm{mg}$ at night with valproate $1,500 \mathrm{mg}$ daily with a satisfactory clinical response.

Masi et al published in 2002 a study evaluating the effectiveness of clozapine in 10 adolescent inpatients with BD 1 (manic and mixed episodes) [15]. Significant improvement with clozapine in resistant cases was noted [14, 15]. The mean dose administered of clozapine was $142.5 \pm 73.6 \mathrm{mg}$ daily with an extreme range of [75-300]. Some of the frequent side effects noted were an elevation of appetite, sedation, enuresis, sialorrhea $[14,15]$. But none was severe enough to warrant decreasing clozapine's doses [14, $15]$.

Degner and colleagues published in 2000 an analysis of 117 retrospectively investigated patients suffering from acute mania who were treated with clozapine given as monotherapy with a mean dosage of $353.4 \pm 76.4 \mathrm{mg}$ daily [16]. Clozapine proved to have excellent antimanic properties $[14,16]$.

Li and colleagues published in 2014 a systematic review of 
clozapine for treatment resistant BD summarizing its efficacy and safety. This review included 15 studies with a total of 1,044 patients and suggests that clozapine may be an effective therapy, safe and well tolerated [3]. Long-term use of clozapine appeared to be associated with improvement in clinical symptoms, measurable social and functional gains, and decreased hospitalization [3].

\section{Conclusion}

Resistant mania is often the cause of significant professional and social repercussions in addition to somatic complications. Despite increasing evidence of efficacy of clozapine in the treatment of resistant bipolar disorder, including resistant mania, clinical reality shows that the initiation of clozapine is often delayed, which reduces the chances of a good therapeutic response. We reported two cases of TRM responsive to clozapine. Further randomized clinical trials remain needed to strengthen its evidence-based indication in TRM and its potential inclusion in international guideline.

\section{Authors' Contributions}

Mohamed Hbib Oun, Rabaa Jomli and Hend Jemli contributed to conception and design.

Mohamed Hbib Oun, Dorsaf Habachi and Amina Aissa contributed to acquisition of data.

Hend Jemli, Samih Madouri were responsible for drafting of the paper.

Uta Ouali, Yosra Zgueb and Rabaa Jomli contributed to critical revision of the paper.

\section{References}

[1] American Psychiatric Association, DSM-5 Task Force. D iagnosticand Statistical Manual of Mental Disorders: DSM$5^{\mathrm{TM}}$. 5th ed. Arlington, VA: American Psychiatric Publishing, Inc; 2013.

[2] Merikangas KR, Jin R, He JP, et al. Prevalence and correlates of bipolar spectrum disorder in the world mental health survey initiative. Arch Gen Psychiatry. 2011; 68 (3): 241-251. doi: 10.1001/archgenpsychiatry.2011.12.

[3] Li XB, Tang YL, Wang CY, de Leon J. Clozapine for treatment-resistant bipolar disorder: a systematic review. Bipolar Disord. 2015 May; 17 (3): 235-47. doi: 10.1111/bdi.12272. Epub 2014 Oct 27. PMID: 25346322.

[4] Bastiampillai T, Gupta A, Allison S, Chan SK. NICE guidance: why not clozapine for treatment-refractory bipolar disorder?
Lancet Psychiatry. 2016; 3 (6): 502-503. doi: 10.1016/S22150366(16)30081-5.

[5] Fountoulakis KN, Yatham LN, Grunze H, et al. The CINP Guidelines on the Definition and Evidence-Based Interventions for Treatment-Resistant Bipolar Disorder. Int J Neuropsychopharmacol. 2020; 23 (4): 230-256. doi: 10.1093/ijnp/pyz064.

[6] Fornaro M, Carvalho AF, Fusco A, et al. The concept and management of acute episodes of treatment-resistant bipolar disorder: a systematic review and exploratory meta-analysis of randomized controlled trials. J Affect Disord. 2020; 276: 970983. doi: 10.1016/j.jad.2020.07.109.

[7] Green AI, Tohen M, Patel JK, et al. Clozapine in the treatment of refractory psychotic mania. Am J Psychiatry. 2000; 157 (6): 982-986. doi: 10.1176/appi.ajp.157.6.982.

[8] Ciapparelli A, Dell'Osso L, Bandettini di Poggio A, et al. Clozapine in treatment-resistant patients with schizophrenia, schizoaffective disorder, or psychotic bipolar disorder: a naturalistic 48-month follow-up study. J Clin Psychiatry. 2003; 64 (4): 451-458. doi: 10.4088/jcp.v64n0416.

[9] Suppes T, Webb A, Paul B, Carmody T, Kraemer H, Rush AJ. Clinical outcome in a randomized 1-year trial of clozapine versus treatment as usual for patients with treatment-resistant illness and a history of mania. Am J Psychiatry. 1999; 156 (8): 1164-1169. doi: 10.1176/ajp.156.8.1164.

[10] Calabrese JR, Kimmel SE, Woyshville MJ, et al. Clozapine for treatment-refractory mania. Am J Psychiatry. 1996; 153 (6): 759-764. doi: 10.1176/ajp.153.6.759.

[11] Tang YL, Mao PX, Jiang F, et al. Clozapine in China. Pharmacopsychiatry. 2008; 41 (1): 1-9. doi: 10.1055/s-2007993224.

[12] Wilkowska A, Wiglusz MS, Cubała WJ. Clozapine in Treatment-Resistant Bipolar Disorder With Suicidality. Three Case Reports. Front Psychiatry. 2019; 10: 520. Published 2019 Jul 19. doi: 10.3389/fpsyt.2019.00520.

[13] Arafat SM, Rahman SM, Haque MM, Shah MA, Algin S, Nahar JS. Clozapine Can Be the Good Option in Resistant Mania. Case Rep Psychiatry. 2016; 2016: 3081704. doi: 10.1155/2016/3081704.

[14] Arafat SMY, Fariduzzaman AM, Uddin MS, Shah MA, Rahman Chowdhury MH. Clozapine in resistant mania: Two case reports. Asian J Psychiatr. 2020; 49: 101953. doi: 10.1016/j.ajp.2020.101953.

[15] Masi G, Mucci M, Millepiedi S. Clozapine in adolescent inpatients with acute mania. $J$ Child Adolesc $\begin{array}{llll}\text { Psychopharmacol. } & \text { 2002; } 12 & \text { (2): 93-99. doi: }\end{array}$ $10.1089 / 104454602760219135$.

[16] Degner D, Bleich S, Müller P, Hajak G, Adler L, Rüther E. Clozapine in the treatment of mania. J Neuropsychiatry Clin Neurosci. 2000; 12 (2): 283. doi: 10.1176/jnp.12.2.283. 